\title{
WHAT A WASTE OF TIME
}

\author{
Søren Wandahl ${ }^{1}$, Hasse H. Neve ${ }^{2}$, and Jon Lerche ${ }^{3}$
}

\begin{abstract}
The elimination of waste is a core focus of lean construction. Reducing waste will increase work efficiency. For several years it has been debated how flow and the efficiency of processes can be measured. Kalsaas, Koskela, and others conclude that in order to operationalize workflow measures, it must be disconnected from productivity and throughput measures and instead focus on work efficiency. However, an extensive and valid baseline of work time efficiency is missing in the community. The establishment of such becomes the objective of this research.

The method is an extensive litterateur review that identified 474 case studies of time waste measures from the 1970s until today. This sample is analyzed in different ways, among others showing that the average direct work time is $43.6 \%$.

The results show that the sample contains considerable uncertainty, which is mainly due to an inconsistent understanding of direct work, indirect work, and waste work in the many different studies. Besides, the results show no statistically significant difference between the performance of varying trades or between countries.

The construction industry can use this research as a baseline for the current direct work level and apply this as a benchmark in a continuous improvement process.
\end{abstract}

\section{KEYWORDS}

Waste, time, work sampling, productivity.

\section{INTRODUCTION}

The construction industry is continuously searching for ways to improve, be more competitive, and generate a higher margin for shareholders and lower costs for customers. In a competitive construction environment, decreasing costs to increase market competitiveness and profits is a common goal among all construction companies. Of all the factors which influence project profits, on-site labor costs are among the most influential (Gouett et al. 2011; Moselhi and Khan 2012). On-site labor costs can be positively and negatively influenced by modern methods of construction, seeking designs and solutions that require fewer labor hours, or implementing production planning and control methods that improve efficiency. In lean construction, efficiency is pursued by removing waste and enhancing flow.

The elimination of waste is a core focus of lean production and construction; see, for example, Koskela (2000). There are seven types of waste in the lean literature:

1 Professor, Dept. of Civil and Architectural Engineering, Aarhus University, Denmark, +45 4189 3216 , swa@cae.au.dk, orcid.org/0000-0001-8708-6035

2 Consultant, Senior Associate, PhD, PwC, Aarhus, Denmark, +45 $2879 \quad 1838$, hasse.hojgaard.neve@pwc.com, orcid.org/0000-0003-2311-3529

3 PostDoc, PhD, Department of Business Development and Technology, Aarhus University, Denmark, +45 6013 3595, jon.lerche@ btech.au.dk, orcid.org/0000-0001-7076-9630 
overproduction, defects, unnecessary inventory, inappropriate processing, excessive transportation, waiting, and unnecessary motion (Ohno 1988). Making-do has later been added as an eighth type of waste (Koskela 2004).

Concerning lean construction, the flow concept was first introduced in the Koskela (1992) seminal work towards a new theory of production in construction. The flow concept's consolidation was achieved with the TFV theory of production in construction (Koskela 2000). Today flow in lean construction is applied with the seven preconditions (Koskela 1999) in the making ready process of the Last Planner System.

Combing flow thinking and waste reduction will result in increased efficiency. Efficiency refers to executing a defined activity with the least possible amount of resources. Unfortunately, construction is challenged in terms of efficiency, as we have many flows and many workers from different trades working in a dynamic environment. Some even argue that construction is inherently wasteful, and as construction is laborintensive, waste and time usage are central topics in the quest for efficient construction. Already in the first IGLC conference back in 1993, this was in focus as Alarcón, L. F. (1993) presented conceptual ideas of modeling waste and time. To measure waste and time usage has been in focus continually in IGLC.

\section{IGLC PAPERS ON WASTE AND TIME}

Waste and time management are two central concepts of lean, thus also popular topics at the IGLC conferences. Currently, the iglc.net conference database contains 1,781 IGLC conference papers. When searching for 'time' and 'waste' in title, keyword, and author, the result is 573 and 417 , respectively. This equals that almost $1 / 3$ of all IGLC papers have the word 'time' in the title and/or in the keywords. When narrowing the search down to the title only, 52 papers has the word 'time' and 54 papers the word 'waste' in the headline. A brief review of IGLC papers addressing time and waste reveals the most important topics, and most cited works seem to be takt time planning. Frandson et al. (2013) was the second earliest published IGLC paper on takt time and now the most cited takt time paper from IGLC with more than 120 citations. In the following years, takt time was in focus. It was conceptually compared and differentiated from LPS (e.g., Emdanat et al. 2016; Frandson et al. 2014) and location-based scheduling (e.g., Frandson et al. 2015; Seppanen et al. 2010). In the recent 3 IGLC conferences, 20 papers on takt time have been published. Around the millennium, Just-in-time was a focal point, where among others, two conceptual papers, each with more than 100 citations, made it clear how JIT should be seen as an integral part of lean construction (Tommelein and Li 1999; Tommelein and Weissenberger 1999).

Several papers have embossed the fundamental understanding of construction as a production system in terms of time usage and time waste. Kalsaas (2010) investigated time waste, both theoretically and empirically. He discussed the relationship of time waste towards the 8 categories of waste (Koskela 2004) and found through case studies that time waste only constitutes around $7 \%$ of work time. This was followed by a case study in 2013 calculating waste time to 35\% (Kalsaas 2013). In IGLC, this work was referred to as measuring workflow and comprised several IGLC publications (Bølviken and Kalsaas 2011; Kalsaas 2012; Kalsaas and Bolviken 2010). However, an extensive and trustworthy review of wasted work time in construction is missing.

Turning the focus to waste, the three most cited IGLC papers on waste are all published around the millennium by well-established Lean Construction researchers Koskela (2004), Formoso et al. (1999), Polat and Ballard (2004). In addition to these, 
Kalsaas is also very active in researching waste in construction, with 8 publications (e.g., Bølviken and Kalsaas 2011; Kalsaas 2010; Kalsaas 2013). Out of the 54 papers on waste, the most common topic is waste as a concept, where authors explore Ohno's (1988) concept of waste in the construction context (Koskela et al. 2013). Among others, this resulted in Bølviken et al.'s (2014) Taxonomy of waste in construction. Over time, this exploration has resulted in Koskela (2004) identifying a $8^{\text {th }}$ waste type of construction, called Making-do. Making-do as a waste refers to a situation where a task is started without all its standard inputs, or the execution of a task is continued although the availability of at least one standard input has ceased (Koskela 2004). In more recent years, several researchers have followed up and further explored making-do (Fireman and Formoso 2013; Fireman and Saurin 2020; Neve and Wandahl 2018), and making-do is now widely recognized as a lead waste type.

Other trends of waste research within IGLC are identifying the sources of waste (e.g., Polat and Ballard 2004; Viana et al. 2012) and waste in relation to design processes and social context (Koskela et al. 2013; Macomber and Howell 2004). Finally, Kalsaas has conducted seminal work on waste in relation to time, productivity, and efficiency, which will be further explored in the next chapter.

\section{Measuring Time Waste in Construction}

In 2010 Kalsaas and Bolviken (2010) wrote "...the current lack of an accepted method for measuring flow in project-based production..." which was the starting point for understanding, defining, and measuring flow or lack of it, i.e., time waste, in construction. Flow is a chain of events without interruptions and closely related to motion, not only of material, but in relation to all preconditions defined by Koskela (2000).

Kalsaas (2010) pointed out that time must be added to the understanding, as "excessive transportation, waiting and unnecessary motion all contain obvious aspects that can be measured in terms of time." Kalsaas conducted, therefore, a small literature study on waste time and collected empirical data through what he called 'the boss method' to conclude on the amount of value-adding worktime (VAW) and non-value-adding worktime (NVAW). VAW and NVAW refer back to Ohno's work (1988, page 138). The conclusion was that $49 \%$ of the time was value-adding. However, as we will later show, both the literature study and the empirical method had limited validity at that time.

Bølviken and Kalsaas (2011) recognized a year later themselves the need for a more valid method for measuring waste time. Thus, they review a number of direct and indirect measurement methods, even though they recognize "...that not all that counts can be counted... On the other hand, we believe that in some cases, measurement can represent an important contribution towards providing a better factual foundation for our improvement work." We strongly agree with this epistemological view. At the same IGLC conference, Kalsaas (2011) concludes on the method selection that a suitable method for measuring workflow should mainly be based on VAW, i.e., the work sampling method.

In Kalsaas (2012), the purpose was to identify the causes for time waste in relation to Koskela's 7 flows, Koskela's $8^{\text {th }}$ flow, and rework in general. The conclusion was that in order to operationalize workflow measures, it must be disconnected from productivity and throughput measures and instead focus on work intensity. In further work, Kalsaas points out that the premise is that flow cannot be understood without an understanding of waste and vice versa (Kalsaas 2013). Also, and perhaps more important, flow, and thus waste, should be measured during the entire production time from start in the morning to end in the afternoon, however excluding regulated breaks. Kalsaas (2013) divides the 
time into VAW and NVAW, where the NVAW has several subcategories like indirect work, planning, HSE, waiting, personal time, rework, etc. This division is very similar to Work Sampling, as presented in, e.g. (Neve and Wandahl 2018; Neve et al. 2020).

\section{WORK SAMPLING}

The work sampling (WS) method has been used since the 1970s to collect data on the amount of value-adding worktime, which is called Direct Work (DW) in the WS method (Gong et al. 2011). The WS method is quantitative and uses direct observations to obtain data on how craftsmen use their work time. The main topic of the published WS studies has throughout time been on how construction can be improved with regards to efficiency, Construction Labor Productivity (CLP), and in the end, construction cost and time. Looking at some of the early work on WS by Thomas (1981), he provides relevant insights on how a WS study can be planned and how the data can be analyzed.

The WS method quantifies how much time craftsmen use on DW and NVAW time. The method is based on direct observations quantified by categorizing them into suitable categories describing the work in focus. The time between each single observation must be randomized in order to avoid cyclic data. All WS studies apply a DW category. However, when it comes to the NVAW category, the picture is more blurred. Some studies categorize all none-DW time as NVAW, while other studies have a more detailed view of NVAW, including a number of subcategories. Generally speaking, NVAW time can in WS be divided into Indirect Work (IW) and Waste Work (WW), resulting in Work Sampling having three categories of time DW, IW, and WW. DW's relation to productivity has been debated throughout time, as DW directly influences the denominator and indirectly the numerator of the productivity equation. Recent studies do, though, concluded that DW is statistically significantly correlated to construction labor productivity on activity, project, and national level (Araujo et al. 2020; Neve et al. 2020).

\section{RESEARCH AIM}

This research aimed to conduct an extensive review to collect the largest sample of DW values in construction ever published. This sample should constitute a valid baseline of DW in construction, which could be applied for benchmark purposes, outline future direction in research, and guide industry in their quest of increasing efficiency of construction.

\section{METHODS}

The main method of this research is an extensive literature review. Several search strategies were combined. Firstly relevant search strings were developed based on pertinent search terms appropriate for the topic, i.e., Work Sampling, Activity Analysis, Waste, Productivity, Direct Work, and Efficiency. The search term was combined with domain terms like construction, building, and construction industry to focus the search on construction. The different search string combinations were applied to three different databases: Google Scholar, ASCE database, and the IGLC paper database. The IGLC paper database was chosen to include the most domain-specific papers and research discourse in the community. The ASCE database was included, as it is clear that Construction Labor Productivity has been a popular research topic for many of the journal papers. Finally, Google Scholar was applied as the largest open-access database. To sort the findings, a number of inclusion and exclusion criteria were applied. Only construction 
work was to be included. Only papers that clearly presented a DW value were included. Multiple publications of the same study were excluded.

This resulted in an initial pile of research papers included in the review. These papers were used to identify further papers by: 1) Examining papers that cited these papers. This was done based on Google Scholar. 2) Reviewing references of each paper to identify possible further literature. 3) Using identified authors to look for additional papers on the same topic from the same authors.

All identified papers were entered into a spreadsheet, including information about authors, year of study, country, DW value, IW and WW values if available, and information about the work observed. The sample was then crosschecked to remove doublets and reviewed to ensure that a DW value from a study was not included twice or more due to multiple publishing sources of the same study. After that, the sample was ready for analysis.

\section{RESULTS}

Previous DW findings were identified in 72 pieces of literature with a total of 474 DW values $(\mathrm{N})$ from WS studies. The literature identified is distributed geographically as follows: North America n=300; Europe N=73; Asia/Australia N=48; Africa N=40; South America $\mathrm{N}=13$. Due to the IGLC page limitation of 10 pages, including references for submission, all the references (72) are omitted.

The 474 entries large sample is without equal the largest ever presented in a Work Sampling literature review. Descriptive statistics are applied to examine the sample, whereafter implications for the IGLC society as well as for the industry are discussed.

A histogram is created for the sample, and this is visually compared with a normal distribution with mean $(\mu)$ and standard deviation $(\sigma)$ from the sample itself, cf. figure 1 .

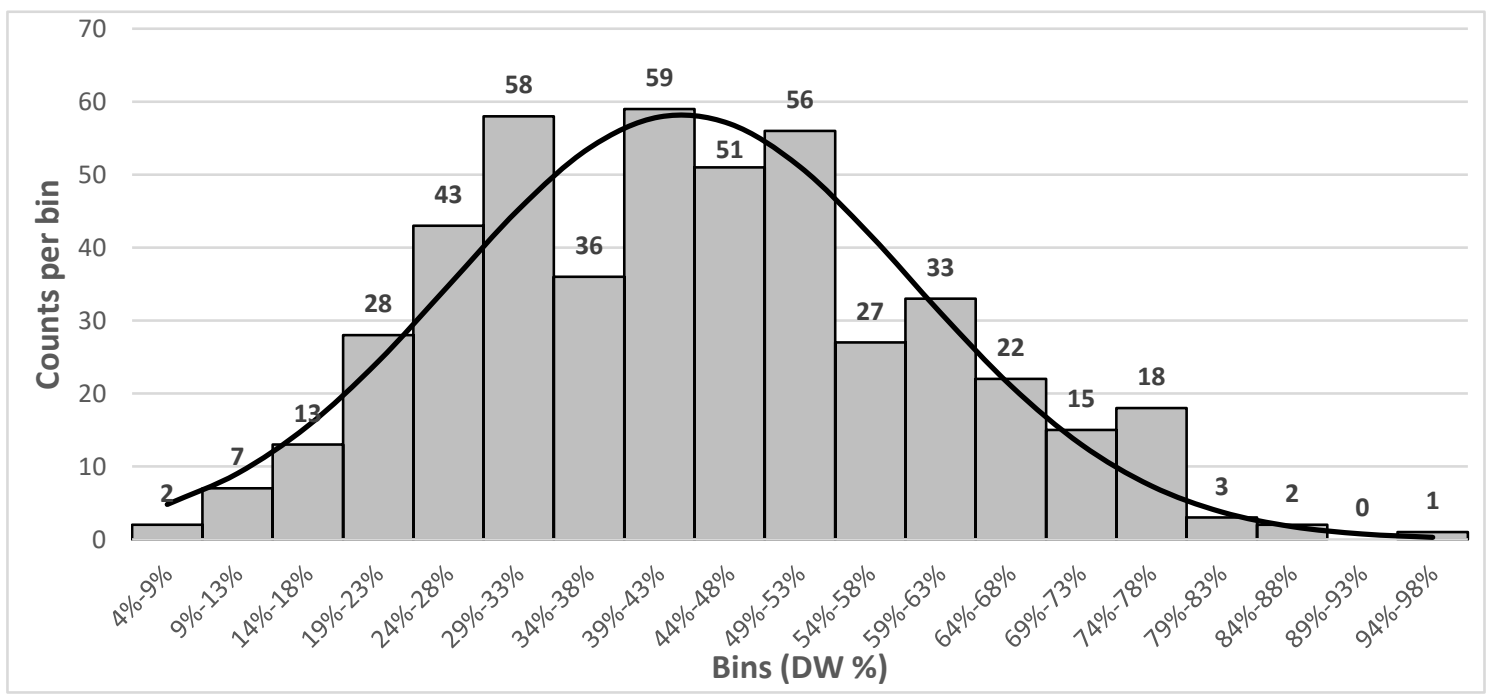

Figure 1. Histogram of $n=474$ DW values from previous findings, and a fitted normal distribution function with $\mu=43.6 \%$ and $\sigma=16.5 \%$

Firstly, the sample is described by mean $\mu=43.6 \%$, standard deviation $\sigma=16.5 \%$, and mode $\mathrm{m}=41 \%$. The large standard deviation indicates large discrepancies in the sample, and it needs to be corrected for outliers before further statistical analysis. The problem is an inconsistent understanding of the work sampling categories, cf. the introduction chapter. Some of the studies have only measured DW $(\mathrm{N}=233)$, while others have 
measured both DW, IW, and WW $(\mathrm{N}=241)$. The problem is that some researchers consider IDW to be part of DW, while others consider IDW to be part of WW. That is why we in the sample can find unrealistic high DW values of, e.g., 98\%. These outliers should be taken into account when analyzing and concluding on the sample.

Visually, the histogram (figure 1) fits very well with the normal distribution function, thus the sample seems to be valid and gaussian as expected. The histogram shows us that the most likely bin is bin 39\%-43\% representing $12 \%$ (count $=59$ ) of the sample. Bins in the interval $[24 \% ; 58 \%$ ] counts 330 data points, thus constitute $70 \%$ of the sample, which is very close to a $\mathrm{z}$-score of 1 . Next, the sample is described as a function of time to investigate any statistically significant developments. This is depicted in figure 2 .

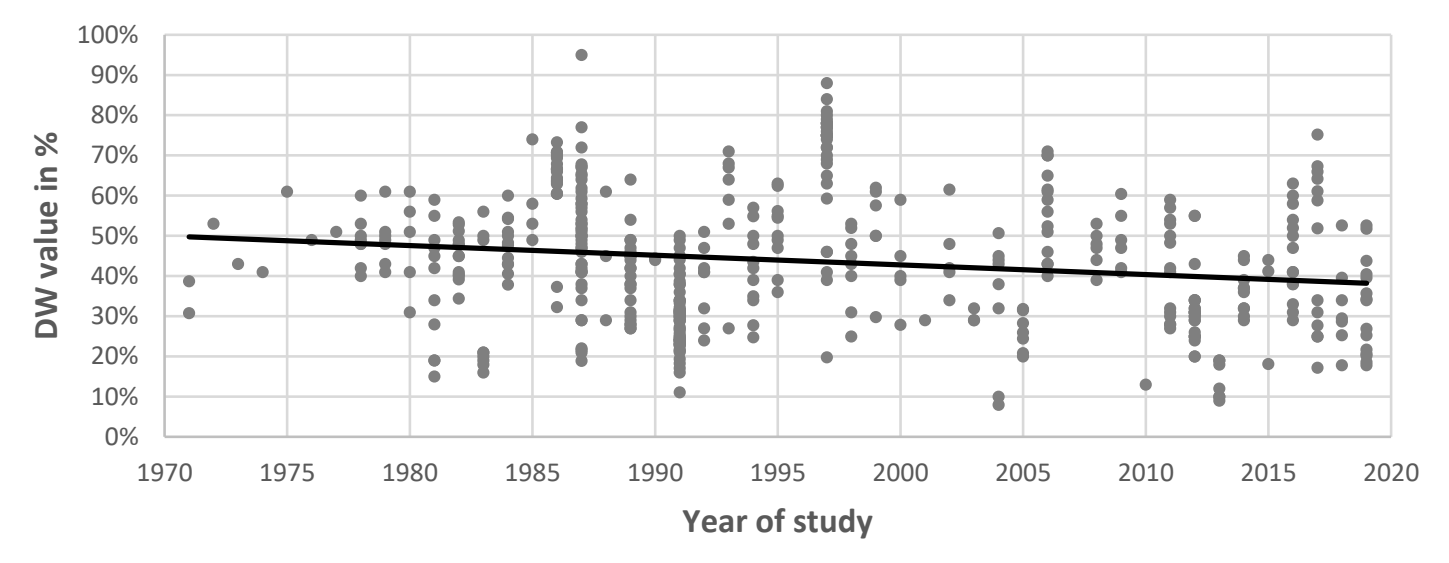

Figure 2. Development over time of $n=474 \mathrm{DW}$ values from previous findings. The linear trendline has $\mathrm{R}^{2}=0.033$.

As seen on the scatter plot in figure 2, there is a weak visual indication of DW's decrease over time. However, the linear regression model has a very weak coefficient of determination $R^{2}=0.033$. Even if outliners are removed from the sample by limiting the sample to only include data points in the interval $\mu \pm \sigma(\mathrm{z}$-score $=1)$, a linear regression model would still have a weak coefficient of determination $\mathrm{R}^{2}=0.062$. Thus there is no significant development in DW over time, as time is not a predictor variable for DW.

Geographically, the samples are distributed over 23 different countries from all continents except Antarctica. Few countries have a large enough sample size to be valid. Only four countries have a sample size of +20 and are based on more than one study. USA $(\mathrm{N}=238)$ has a mean of $\mu=39.8 \%$ and $\sigma=11.7 \%$. Canada $(\mathrm{N}=63)$ has a mean of $\mu=47.3 \%$ and $\sigma=16.7 \%$. Denmark $(\mathrm{N}=25)$ has a mean of $\mu=33.1 \%$ and $\sigma=11.0 \%$. Norway $(\mathrm{N}=20)$ has a mean of $\mu=58.6 \%$ and $\sigma=11.2 \%$. Norway stands out with a larger mean than the other countries, and the Canadian samples have a larger standard deviation than the other countries. Generally speaking, the DW baseline is in the range of $30-40 \% \pm 10 \%$. There is no indication that the country should be a predictive variable for DW.

Many of the studies do not precisely inform what kind of work was observed in the Work Sampling study, or the study includes several trades not separated. These are from now on called unspecified. Table 1 shows DW values divided by type of trade work.

As shown in table 1, 291 out of 474 DW values have not precisely defined the observed kind of trade. The remaining 183 DW values are fairly distributed between seven generic types of trade work. The standard deviation is relatively high for all the named trades, thus one cannot conclude that the trade is correlated with the effectiveness of the work. Therefore, the type of work is not a predictor variable for DW. 
Table 1: WS studies grouped by kind of trade with more than 10 samples per trade and based on more than one source of research $(\mathrm{N}=474)$.

\begin{tabular}{cccc}
\hline Trade & Sample $(\mathbf{N})$ & Mean $(\boldsymbol{\mu})$ & Std. dev. $(\boldsymbol{\sigma})$ \\
\hline Brick \& Tiles & 27 & $46.2 \%$ & $13.2 \%$ \\
Carpenter & 26 & $43.9 \%$ & $15.7 \%$ \\
Civil & 10 & $31.2 \%$ & $9.6 \%$ \\
Concrete & 48 & $38.8 \%$ & $19.0 \%$ \\
Electrical & 22 & $47.4 \%$ & $16.5 \%$ \\
HVAC & 25 & $32.0 \%$ & $16.1 \%$ \\
Steel & 25 & $41.3 \%$ & $20.4 \%$ \\
Unspecified or mixed & 291 & $45.9 \%$ & $15.6 \%$ \\
\hline
\end{tabular}

\section{DISCUSSION}

The result showed a baseline where direct work constitutes $43.6 \%$ of the work time. The review also showed that there was some discrepancy in the categories. Several unalike categorizations have been applied in the different studies. Some studies apply only the DW category. Others use three categories, namely DW, IW, and WW. Some consider IW as a part of DW, and so continues the inconsistency. Two important learnings should be drawn from this. Firstly, the current baseline of $\mu=43.6 \%$ contains a relatively considerable uncertainty, which is also reflected in $\sigma=16.5 \%$. Secondly, the application of work sampling and other methods of measuring wasted work time needs a more unified guideline and application. The following taxonomy is recommended Direct Work (DW) $=$ Producing. Indirect Work $(\mathrm{IW})=$ Talking, Preparing, and Transporting. Waste Work $(\mathrm{WW})=$ Walking, Waiting, and Gone .

Returning to the question of whether the indirect work (talking, preparation, and transportation) should be considered waste or value-adding. Many practitioners have argued that it should be regarded as value-adding, as one cannot imaging a construction project without transportation, preparation, and talk for coordination. This is needed to complete the tasks, they argue. On the other hand, Lean theory argues that activity either adds value (transforms) or is considered waste. The distinction between DW and IW depends on the perspective that is considered. If you observe a site cleaning crew, cleaning is DW. If you observe an HVAC crew do cleaning, it is IW. Imagine two identical tasks $\mathrm{A}$ and $\mathrm{B}$, but with a different distribution of the work time, as illustrated in figure 3.

Task A and B have the same amount of walking, waiting, and gone, but task A has more production time and less talking, preparation, and transportation than task B. Which task do you think will be completed first, task A or B? The answer can only be that task A will complete faster than task B. Thus, in order to be efficient, it is now clear that we need to minimize time spend on IW (talk, preparation, and transportation). Of course, the same count for the Waste Work, which also needs to be reduced.

The conclusion and also the recommendation of this research are therefore clear. 1) We should apply Work Sampling to get a data-driven approach and to measure our waste time. 2) Work Sgampling must include categories of DW, IW, and WW. 3) We must aim to have as much DW as possible. Moreover, WS should be used to identify waste and NVAW. 


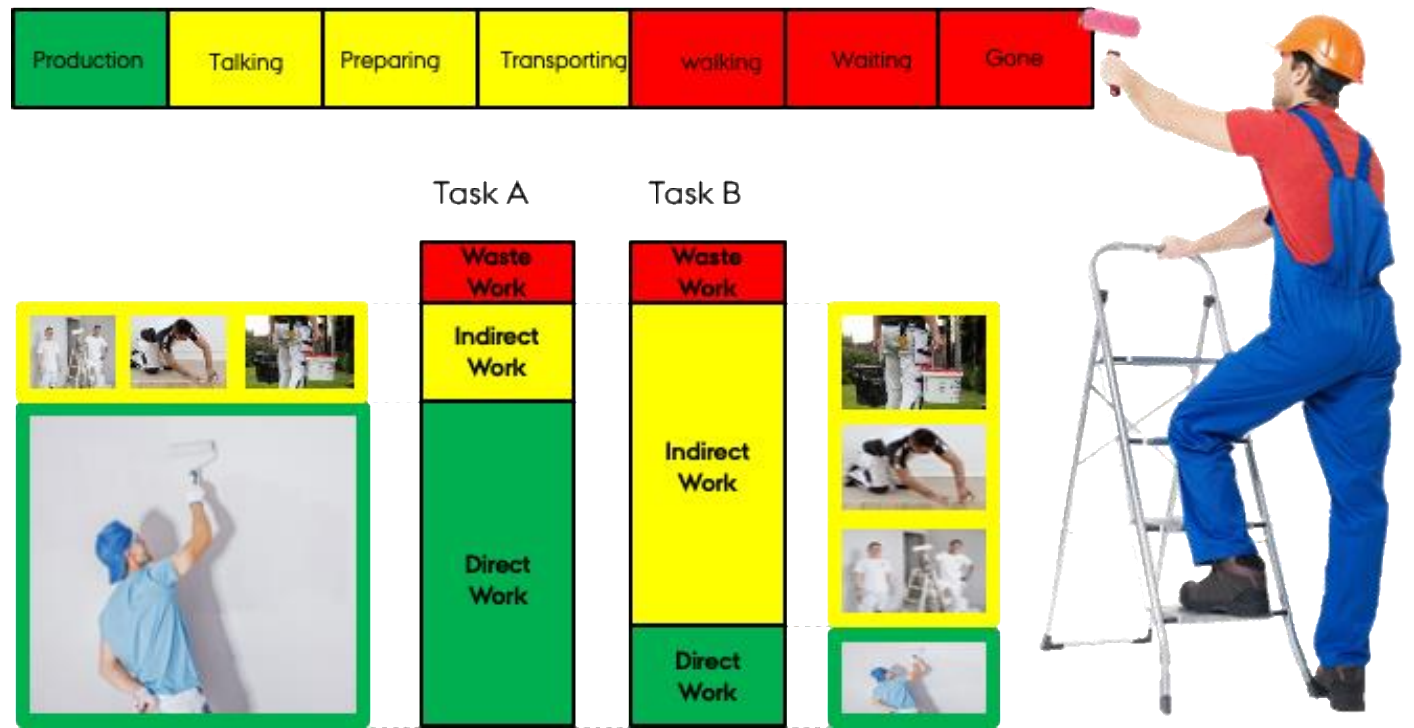

Figure 3. Two identical painting tasks, but with two different distributions of work time.

This review contributes to the Body-of-Knowledge with a large and significant baseline of DW. Practitioners can apply this baseline for benchmarking purposes by using the sample's cumulative distribution function, as illustrated in figure 4. As pointed out, the sample includes different use of Work Sampling taxonomy, which challenges the validity of this study. Adding to this is the fact that direct work can include both re-work and making-do. Very few of the studies in the sample relate critically to this. Academic and practitioner should though use this study carefully for generalizing purpose, whereas WS as method to improve a single project is with high validity.

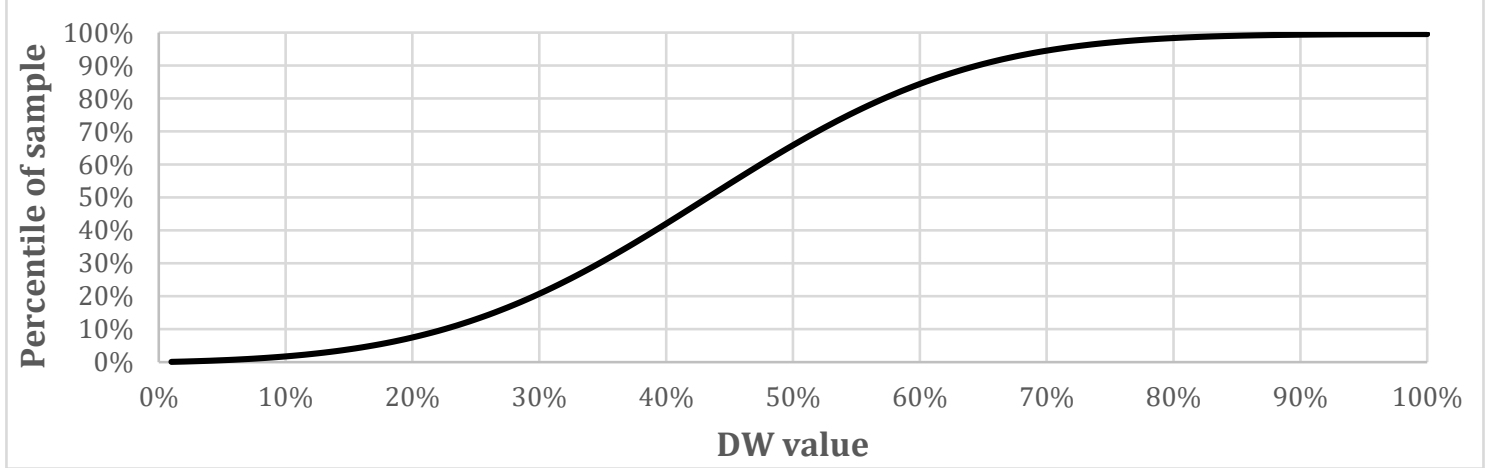

Figure 4. Cumulative Distribution Function of the DW sample ( $n=474)$.

The final part of the discussion is the connection between DW and CLP. For a starting point, one could argue that DW and CLP are not alike and not connected. CLP is an indicator of how much output is generated per resource use. DW and Work Sampling is one the contrary an indicator for efficiency and not directly linked to the output. Are there then no connections between DW and CLP? Indeed there is. The more efficient you are, i.e., the higher percentage of Direct Work, the less resource you need to produce. Resource usage is the denominator in the CLP formula; thus, the higher DW, the less resource, the higher is the productivity. This is logic!.

Nonetheless, this logic has rarely been quantified and proven in research. Recent studies do, though, concluded that DW is statistically significantly correlated to construction labor productivity on activity, project, and national level (Araujo et al. 2020; Neve et al. 2020; Siriwardana et al. 2017). 


\section{CONCLUSION}

This research aimed to conduct an extensive review to collect the largest sample of DW values in construction ever published and constitute a valid baseline of DW in construction, which could be applied for benchmark purposes. The research succeeded by identifying 474 case studies of DW measures origin from 72 different publications. The sample was confirmed to be a normal distribution with a mean DW value of $43.6 \%$, with a standard deviation of $16.5 \%$. An effect of these results is the outline of some recommendations for the lean construction community regards waste work time and construction site efficiency. The first recommendation is to apply a more stringent taxonomy for data collection in work sampling, including three categories, Direct Work, Indirect Work, and Waste Work. The second recommendation is to apply work sampling as much as possible to enhance a data-driven approach to flow optimization. Third and final recommendation is that the optimization should focus mainly on direct work and aim to increase this as much as possible, as indirect work has to be considered waste in the purest definition of lean.

\section{REFERENCES}

Araujo, L. O. C., Neto, N. R., and Caldas, C. H. (2020). "Analyzing the Correlation between Productivity Metrics." Construction Research Congress 2020.

Bølviken, T., \& Kalsaas, B. T. (2011). "Discussion of Strategies for Measuring Workflow in Construction." Proc. 19th Ann. Conf. Int. Group for Lean Constr., Lima, Peru.

Bølviken, T., Rooke, J., and Koskela, L. (2014). "The Wastes of Production in Construction - a TFV Based Taxonomy." Proc. 22nd Ann. Conf. Int. Group for Lean Constr., Oslo, Norway.

Emdanat, S., Linnik, M., and Christian, D. (2016). "A Framework for Integrating Takt Planning, Last Planner System and Labor Tracking." Proc. 24th Ann. Conf. Int. Group for Lean Constr., Boston, USA.

Fireman, M. C. T., and Formoso, C. T. (2013). "Integrating Production and Quality Control: Monitoring Making-Do and Unfinished Work." Proc. 21st Ann. Conf. Int. Group for Lean Constr., Fortaleza, Brazil.

Fireman, M. C. T., and Saurin, T. A. (2020). "Chain of Wastes: The Moderating Role of Making-Do." Proc. 28th Ann. Conf. Int. Group for Lean Constr., Berkeley, USA.

Formoso, C., Isatto, E., \& Hirota, E. (1999). "Method for Waste Control in the Building Industry." Proc. 7th Ann. Conf. Int. Group for Lean Constr., Berkeley, USA.

Frandson, A., Berghede, K., and Tommelein, I. D. (2013). "Takt Time Planning for Construction of Exterior Cladding." Proc. 21st Ann. Conf. Int. Group for Lean Constr., Fortaleza, Brazil.

Frandson, A., Berghede, K., and Tommelein, I. (2014). "Takt-Time Planning and the Last Planner." Proc. 22nd Ann. Conf. Int. Group for Lean Constr., Oslo, Norway.

Frandson, A. G., Seppänen, O., and Tommelein, I. D. (2015). "Comparison Between Location-Based Management and Takt Time Planning." Proc. 23rd Ann. Conf. Int. Group for Lean Constr., Perth, Australia.

Gong, J., Borcherding, J. D., and Caldas, C. H. (2011). "Effectiveness of craft time utilization in construction projects." Const, Mgmt. \& Eco., 29(July), 737-751.

Gouett, M., Hass, C., Goodrum, P., \& Caldas, C. (2011). "Activity Analysis for DirectWork Rate Improvement." Const, Mgmt. \& Eco, 137(12), 1117-1124.

Kalsaas, B. T. (2010). "Work-Time Waste in Construction." Proc. 18th Ann. Conf. Int. Group for Lean Constr., Hafia, Israel. 
Kalsaas, B. T. (2011). "On the Discourse of Measuring Work Flow Efficiency in Construction. A Detailed Work Sampling Method." Proc. 19th Ann. Conf. Int. Group for Lean Constr., Lima, Peru.

Kalsaas, B. T. (2012). "Further Work on Measuring Workflow in Construction Site Production." Proc. 20th Ann. Conf. Int. Group for Lean Constr., San Diego, USA.

Kalsaas, B. T. (2013). "Measuring Waste and Workflow in Construction." Proc. 21st Ann. Conf. Int. Group for Lean Constr., Fortaleza, Brazil.

Kalsaas, B. T., \& Bolviken, T. (2010). "The Flow of Work in Construction: A Conceptual Discussion." Proc. 18th Ann. Conf. Int. Group for Lean Constr., Hafia, Israel.

Koskela, L. (1992). "Application of the new production philosophy to construction." CIFE Technical Report 72. Stanford University.

Koskela, L. (1999). "Management of Production in Construction: A Theoretical View." Proc. 7th Ann. Conf. Int. Group for Lean Constr., Berkeley, USA.

Koskela, L. (2004). "Making-Do - the Eighth Category of Waste." Proc. 12th Ann. Conf. Int. Group for Lean Constr., Helsingфr, Denmark.

Koskela, L., Bølviken, T., \& Rooke, J. (2013). "Which Are the Wastes of Construction?" Proc. 21st Ann. Conf. Int. Group for Lean Constr., Fortaleza, Brazil.

Macomber, H., and Howell, G. (2004). "The Two Great Wastes in Organizations." Proc., Proc. 12th Ann. Conf. Int. Group for Lean Constr., Helsing $\phi r$, Denmark.

Moselhi, O., and Khan, Z. (2012). "Significance ranking of parameters impacting construction labour productivity." Construction Innovation, 12(3), 272-296.

Neve, H. H., and Wandahl, S. (2018). "Towards Identifying Making-Do as Lead Waste in Refurbishment Projects." Proc. 26th Ann. Conf. Int. Group for Lean Constr., Chennai, India.

Neve, H. H., Wandahl, S., Lindhard, S., Teizer, J., and Lerche, J. (2020). "Determining the Relationship between Direct Work and Construction Labor Productivity in North America: Four Decades of Insights." Journal of Construction Engineering and Management, 146(9), 04020110.

Neve, H. H., Wandahl, S., Lindhard, S., Teizer, J., and Lerche, J. (2020). "Learning to see value-adding and non-value-adding work time in renovation production systems." Production Planning and Control.

Ohno, T. (1988). "Toyota Production System.” Productivity Press, New York

Polat, G., and Ballard, G. (2004). "Waste in Turkish Construction: Need for Lean Construction Techniques." Proc., Proc. 12th Ann. Conf. Int. Group for Lean Constr., Helsing $\phi r$, Denmark.

Seppanen, O., Ballard, G., and Pesonen, S. (2010). "The Combination of Last Planner System and Location-Based Management System." Proc. 18th Ann. Conf. Int. Group for Lean Constr., Hafia, Israel.

Thomas, H. R. (1981). "Can work sampling lower construction costs." Journal of Construction Division, 107(2), 263-278.

Tommelein, I. D., and Li, A. E. Y. (1999). "Just-in-Time Concrete Delivery: Mapping Alternatives for Vertical Supply Chain Integration." Proc. 7th Ann. Conf. Int. Group for Lean Constr., Berkeley, USA.

Tommelein, I. D., and Weissenberger, M. (1999). "More Just-in-Time: Location of Buffers in Structural Steel Supply and Construction Processes." Proc. 7th Ann. Conf. Int. Group for Lean Constr., Berkeley, USA. 